\title{
Stage IA Breast Cancer AJCC v7
}

National Cancer Institute

\section{Source}

National Cancer Institute. Stage IA Breast Cancer A/CC v7. NCI Thesaurus. Code C85835.

Stage IA includes: T1, N0, M0. T1: Tumor $20 \mathrm{~mm}$ or less in greatest dimension. T1 includes T1 mi. T1 mi: Tumor $1 \mathrm{~mm}$ or less in greatest dimension. N0: No regional lymph node metastasis. M0: No clinical or radiographic evidence of distant metastasis. MO includes $\mathrm{MO}(\mathrm{i}+)$. (AJCC 7th Ed.) 